\title{
Association between injury severity and amyloid $\beta$ protein levels in serum and cerebrospinal fluid in rats with traumatic spinal cord injury
}

\author{
LEI GUO $^{1,2^{*}}$, JINGMING HOU ${ }^{3 *}$, JIANFENG ZHONG $^{2}$, JIA LIU $^{2}$, TIANSHENG SUN $^{2}$ and HONGLIANG LIU ${ }^{3}$ \\ ${ }^{1}$ Department of Spine Surgery, PLA No. 252 Hospital, Baoding, Hebei 071000; ${ }^{2}$ Department of Orthopedics, \\ Chinese PLA Beijing Army General Hospital, Beijing 100700; ${ }^{3}$ Department of Rehabilitation, \\ Southwest Hospital, Third Military Medical University, Chongqing 400038, P.R. China
}

Received November 15, 2015; Accepted December 9, 2016

DOI: 10.3892/mmr.2017.6261

\begin{abstract}
The aim of the present study was to determine whether amyloid- $\beta(\mathrm{A} \beta)$ protein could be detected in the serum and cerebrospinal fluid (CSF) of rats with traumatic spinal cord injury (SCI) and whether $\mathrm{A} \beta$ protein levels in serum and CSF correlated with the injury severity. A total of 140 adult female Sprague-Dawley rats were randomly divided into four groups: Sham, mild injury, moderate injury and severe injury. Serum and CSF samples were collected at 12 h, 1, 3, 7, 14, 21 and 28 days post-injury. ELISA analysis for serum and CSF $\mathrm{A} \beta$ protein was performed. Locomotor function of all animals was assessed using the Basso, Beattie and Bresnahan (BBB) locomotor rating scale. Following SCI, the protein levels of $\mathrm{A} \beta$ in serum and CSF samples from SCI groups significantly increased from $12 \mathrm{~h}(\mathrm{P}<0.05)$ and peaked 3 days after injury. A significant increase of $A \beta$ levels in serum and CSF in the severe SCI group was also observed at 28 days after injury $(\mathrm{P}<0.05)$. At 28 days after injury the protein levels of $A \beta$ in serum and CSF were significantly correlated with the severity of injury (serum, $\mathrm{R}^{2}=-0.806, \mathrm{P}<0.01 ; \mathrm{CSF}, \mathrm{R}^{2}=-0.694, \mathrm{P}<0.01$ ). A significant correlation between $A \beta$ protein level in serum and CSF and neurological deficits (BBB score) was also observed $(\mathrm{P}<0.01)$. The protein level of $A \beta$ in serum and $C S F$
\end{abstract}

Correspondence to: Dr Hongliang Liu, Department of Rehabilitation, Southwest Hospital, Third Military Medical University, 30 Gaotanyan Centre Street, Shapingba, Chongqing 400038, P.R. China

E-mail: liuhongliangkf@163.com

Dr Tiansheng Sun, Department of Orthopedics, Chinese PLA Beijing Army General Hospital, 5 Nanmencang, Dongcheng, Beijing 100700, P.R. China

E-mail: suntiansheng-@163.com

${ }^{*}$ Contributed equally

Key words: spinal cord injury, amyloid- $\beta$, injury severity, cerebrospinal fluid, serum, biomarker was severity and time-dependent during the acute phase in rats with traumatic SCI. Monitoring the level of $\mathrm{A} \beta$ protein in serum may improve the evaluation of SCI severity and the neuron functional status following SCI.

\section{Introduction}

Spinal cord injury (SCI) is characterized by sensorimotor deficits below the injury and suffers from a lack of effective treatment. Previous studies have aimed to evaluate the severity and the potential for recovery in patients with traumatic SCI; however, reliable methods for this and prediction of the outcome following traumatic SCI, particularly in the acute stages remain to be elucidated $(1,2)$. The current evaluation methods of injury severity of traumatic SCI is predominantly limited to neurological evaluation and imaging studies, which is often imprecise due to the unstable condition of patients, with occurrences such as spinal shock and the artifacts of metal implants following spinal operations (3-6). This contributes to the difficulty of developing novel treatments for patients with SCI.

Recently, increasing experimental evidence has demonstrated that SCI should be considered a neurodegenerative disease $(7,8)$. A previous study determined that there was degenerative evidence for structural changes in the brain during the early stage of SCI using high-field structural magnetic resonance imaging (MRI) (9). Previous studies revealed that neuron degeneration may be part of SCI pathology. In degenerative diseases, such as multiple sclerosis (MS), amyotrophic lateral sclerosis (ALS), and Alzheimer's disease, amyloid- $\beta$ (A $\beta)$ deposition occurs as a marker for neuron degeneration (10-12). Changes in $A \beta$ concentration in serum and cerebrospinal fluid (CSF) were considered to be an indication of the severity of injury to the blood-brain barrier and neuron degeneration in the central nervous system (CNS) $(13,14)$. A recent study reported an increase in $A \beta$ protein levels in a lesion site of spinal cord in SCI model of rats (15). However, to the best to our knowledge the present study is the first to determine whether $\mathrm{A} \beta$ protein levels in serum and CSF are associated with injury severity in SCI. The present study quantified $A \beta$ protein levels in serum and CSF in 
rats with traumatic SCI. The primary aims were to determine whether $\mathrm{A} \beta$ protein was detectable in serum and CSF samples of traumatic SCI and whether $A \beta$ protein level reflected the severity of the injury.

\section{Materials and methods}

Experimental animals and grouping. All experiments were performed in accordance with the guidelines established by the Animal Ethics Committee of Chinese PLA Beijing Army General Hospital (Beijing, China). A total of 140 adult female Sprague-Dawley rats (age, 8-9 months; weight, 220-260 g) were purchased from Beijing Haidian Thriving Experimental Animal Center (Beijing, China). All rats were housed in a climate-controlled closed facility with $12 \mathrm{~h}$ light/dark cycles at $24 \pm 2^{\circ} \mathrm{C}$ and free access to food and water for 1 week prior to the experimental procedures. All rats were randomly and equally divided into four groups ( $\mathrm{n}=35$ per group).

SCI model induction. Rats were anesthetized via intraperitoneal injection of $10 \%$ chloral hydrate $(3.0 \mathrm{mg} / \mathrm{kg}$ body weight; Shanghai Golden Harvest Biotechnology Co., Ltd., Shanghai, China). The graded contusion model of SCI was performed using the New York University-Multicenter Animal Spinal Cord Injury Study (NYU-MASCIS) impactor as previously described (16). Briefly, a laminectomy was performed at T8 level to expose the spinal cord, and a contusion lesion was produced with the NYU-MASCIS impactor by dropping a $10 \mathrm{~g}$ rod onto the exposed dorsal surface of the spinal cord from the following specific heights: i) Mild group (SCI-M), $12.5 \mathrm{~mm}$; ii) moderate group (SCI-Mo), $25 \mathrm{~mm}$; and iii) severe group (SCI-S), $50 \mathrm{~mm}$. Rats in the sham group received laminectomy only. Following the operation, rats were placed back to their cages with heating pads and closely observed until they woke up. As prophylactic for infections, 200,000 U/animal/day penicillin was administered subcutaneously for 3 consecutive days following the operation. Saline was injected subcutaneously immediately following development of the lesion and then daily for 7 days. Food and water were provided ad libitum. Postoperative care included manual expression of bladders twice a day until the rats were sacrificed or bladder function recovered.

Behavioral testing. Locomotor functions of all animals were assessed using the Basso, Beattie and Bresnahan (BBB) locomotor rating scale (17). BBB is a 21-point scale used to assess and analyze the hindlimb movements of rats in open-field, at $12 \mathrm{~h}$ and 1, 3, 7, 14, 21 and 28 days after the operation. Two investigators, who were blinded to experimental design, assessed the motor function in all the animals.

ELISA and western blotting. Rats were sacrificed by intraperitoneal injection of lethal dose of $10 \%$ chloral hydrate (30 mg/kg body weight), at $12 \mathrm{~h}, 1,3,7,14,21$ and 28 days post injury $(n=4)$ after surgery, for the sham group, laminectomy only. Blood samples $(5 \mathrm{ml})$ were taken from the tail vein of the injured rats at $12 \mathrm{~h}, 1,3,7,14,21$ and 28 days. CSF samples (100 $\mu \mathrm{l})$ were collected by lumbar puncture at the same time point. The blood samples were anticoagulated using ethylenediamine tetraacetic acid and centrifuged at 1,368 $\mathrm{xg}$ for $10 \mathrm{~min}$ at room temperature to obtain plasma. Plasma and CSF samples were stored at $-80^{\circ} \mathrm{C}$ prior to analysis of the protein levels of $\mathrm{A} \beta$ by ELISA. Proteins for ELISA and western blotting were sequentially extracted as previously described (18), from a total $5 \mathrm{~mm}$ spinal cord tissue $(2.5 \mathrm{~mm}$ rostral and $2.5 \mathrm{~mm}$ caudal to the injury site) using diethylamine (DEA) and radioimmunoprecipitation assay buffer. A commercially available kit (rat $A \beta_{1-42}$ ELISA kit) from Xinfan Biotechnology Corporation (Shanghai, China) was used to detect endogenous soluble rat $\mathrm{A} \beta_{1-42}$, as per manufacturer's protocol from the DEA extraction. Anti-A $\beta_{1-42}$ antibody (cat. no. ab10148) for western blotting was purchased from Abcam (Cambridge, UK). Western blot analysis was performed as previously described (19). Total protein (20 $\mu \mathrm{g}$ for each) was separated on $10 \%$ sodium dodecyl sulfate polyacrylamide gels and transferred onto nitrocellulose membranes. The membranes were first blocked with 5\% skimmed milk and then incubated with rabbit anti-A $\beta$ (ab10148; 1:500) or anti- $\beta$-actin (ab129348; 1:1,000; Abcam) overnight at $4^{\circ} \mathrm{C}$. After 5 washes in $1 \mathrm{X}$ PBST, membranes were incubated with appropriate horseradish peroxidase conjugated affinity purified secondary antibody (AP187P; 1:1,000; EMD Millipore, Billerica, MA, USA) for $1 \mathrm{~h}$ at $37^{\circ} \mathrm{C}$, developed using an enhanced chemiluminescence kit (Thermo Fisher Scientific, Inc., Waltham, MA, USA) for detection of proteins. Pixel intensity for each sample and its corresponding $\beta$-actin was determined on three different blots using ImageJ software (imagej.nih.gov/ij/). To quantify the results, samples were normalized to $\beta$-actin and a bar chart was produced using GraphPad Prism version 5 (GraphPad Software, Inc., San Diego, CA, USA).

Statistical analysis. Data are expressed as the mean \pm standard deviation and were analyzed using SPSS version 19.0 (IBM SPSS, Armonk, NY, USA). One-way analysis of variance, followed by the Student-Newman-Keuls test were used to determine the differences between groups. The association between variables was determined by the correlation coefficient method according to the Spearman or Pearson methods. $\mathrm{P}<0.05$ was considered to indicate a statistically significant difference.

\section{Results}

Behavioral scoring. Significant differences in the behavioral score using the BBB locomotor rating scale between the SCI groups and the sham group were identified $(\mathrm{P}<0.05)$. Higher SCI injury groups had significantly lower behavioral scores $(\mathrm{P}<0.05$; Fig. 1). Over the period of four weeks, gradual recovery was observed in all the SCI groups. Significant motor functional improvement was detected in the mild SCI group when compared with moderate and severe SCI group 12 at 7 , 10,14 and 28 days after SCI $(\mathrm{P}<0.05)$.

A $\beta$ protein levels in serum and CSF of SCI rats. Serum and CSF $\mathrm{A} \beta$ protein levels observed were similar (Figs. 2 and 3 ). In the sham group, the serum and CSF A $\beta$ levels were low for all time points. The A $\beta$ levels in SCI-S group at $12 \mathrm{~h}$ after injury were significantly increased compared with the sham group $(\mathrm{P}<0.05$; Fig. 2). At 1 and 3 days after injury, the serum $A \beta$ protein levels were increased significantly in all SCI groups $(\mathrm{P}<0.05$; Fig. 2$)$. It is of note that the serum A $\beta$ levels in the SCI-M group were significantly reduced compared with the SCI-Mo and SCI-S 


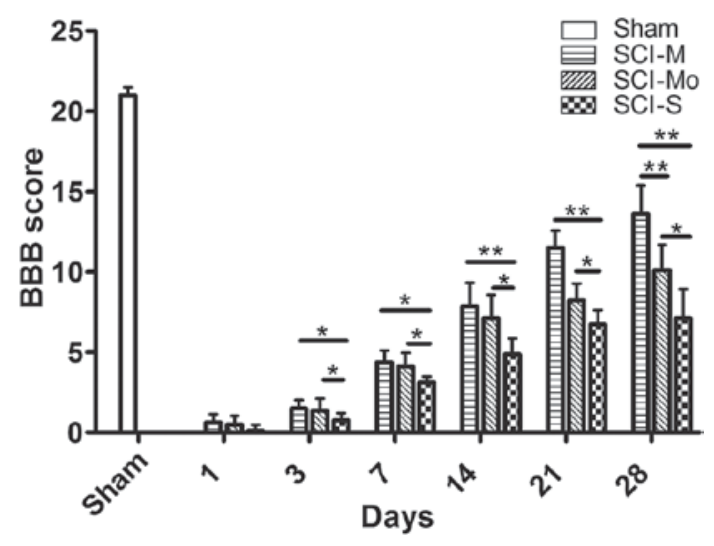

Figure 1. BBB score following SCI $(n=4)$. ${ }^{*} \mathrm{P}<0.05,{ }^{* *} \mathrm{P}<0.01$ vs. sham $/ \mathrm{SCI}$ group. BBB score, Basso, Beattie and Bresnahan score; SCI, spinal cord injury; SCI-M, SCI-mild group; SCI-Mo, SCI-moderate group; SCI-S, SCI-severe group.

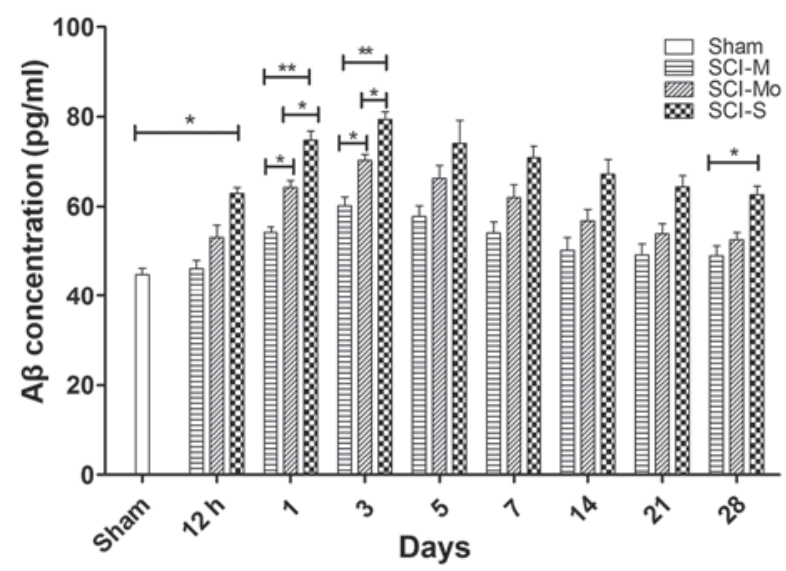

Figure 2. $A \beta$ protein levels in serum following SCI $(n=4) .{ }^{*} \mathrm{P}<0.05$ vs. sham/or SCI groups, ${ }^{* *} \mathrm{P}<0.01$ vs. SCI-M group. $\mathrm{A} \beta$, amyloid- $\beta$; SCI, spinal cord injury; SCI-M, SCI-mild group; SCI-Mo, SCI-moderate group; SCI-S, SCI-severe group.

groups at 3 days $(\mathrm{P}<0.05$; Fig. 2). Subsequently, the serum $\mathrm{A} \beta$ levels were gradually reduced in all SCI groups; however, $\mathrm{A} \beta$ expression level was significantly higher in the SCI-S group compared with the SCI-M group at 28 days after injury $(\mathrm{P}<0.05$; Fig. 2). The CSF A $\beta$ level in the SCI-S group was significantly higher compared with SCI-M group $(\mathrm{P}<0.01)$ and SCI-Mo group $(\mathrm{P}<0.05)$ at 1 and 3 days after injury (Fig. 3). At 28 days after injury, $\mathrm{A} \beta$ levels in the SCI-S group were significantly higher compared with the SCI-M and SCI-Mo groups at 28 days after injury $(\mathrm{P}<0.05$; Fig. 3$)$.

$A \beta$ protein levels in injured spinal cord tissue. To determine whether the increase of $A \beta$ in injured spinal cord tissue may be associated with the protein expression levels observed in serum and CSF, rats in moderate group $(n=4)$ were sacrificed at $12 \mathrm{~h}, 1,3,7,14,21$ and 28 days and an ELISA was performed to detect the $A \beta$ changes in tissues following injury. Over the course of the experiment, changes of $A \beta$ protein levels in injured spinal cord tissue were similar to those occurred in CSF. The A $\beta$ protein levels in spinal cord tissues were significantly higher in the SCI-M group at 1 and 3 days after injury compared with the sham group ( $\mathrm{P}<0.05$; Fig. 4). Rats in all

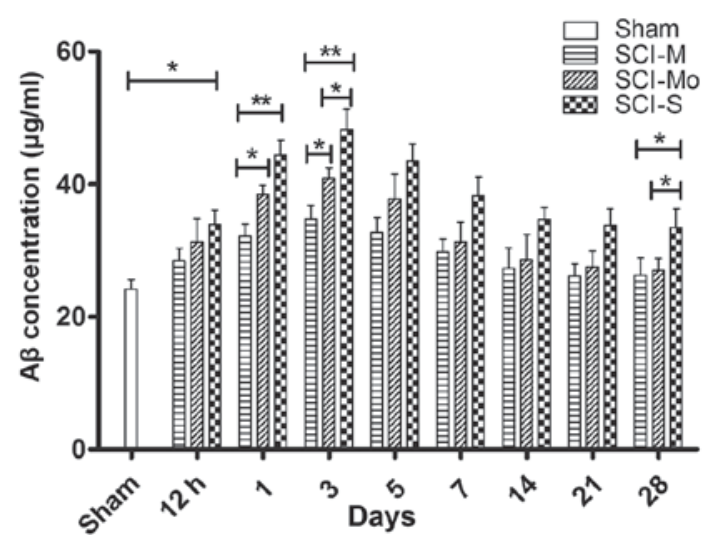

Figure 3. A $\beta$ protein levels in cerebrospinal fluid following SCI $(n=4)$ ${ }^{*} \mathrm{P}<0.05$ vs. sham/or SCI groups. ${ }^{* *} \mathrm{P}<0.01$ vs. SCI-M group. $\mathrm{A} \beta$, amyloid- $\beta$; SCI, spinal cord injury; SCI-M, SCI-mild group; SCI-Mo, SCI-moderate group; SCI-S, SCI-severe group.

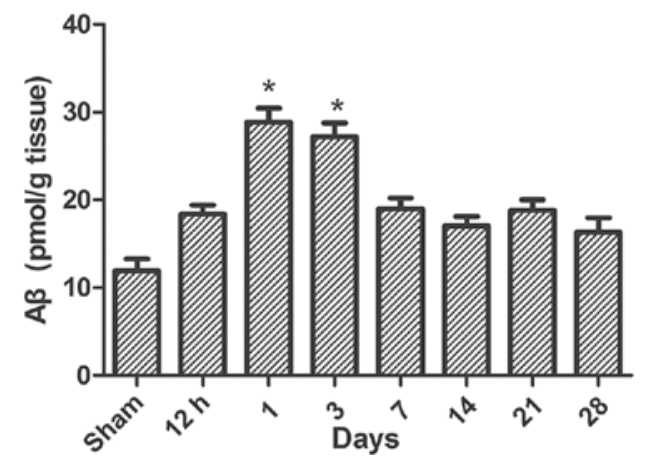

Figure 4. $A \beta$ protein content in injured spinal cord tissue of spinal cord injury-moderate group $(n=4)$. ${ }^{*} \mathrm{P}<0.05$ vs. sham group. $A \beta$, amyloid- $\beta$.

the SCI groups and the sham group $(n=4)$ were then sacrificed 3 days after injury and western blots were performed to detect changes in injured spinal cord tissue. The $A \beta$ protein level in the SCI-S group was significantly higher compared with the SCI-M group at 3 days after injury ( $\mathrm{P}<0.05$; Fig. 5).

Correlation analysis between the serum and CSF A $\beta$ levels and $B B B$ score. The serum and CSF A $\beta$ levels peaked at 3 days after injury and a significant difference between the SCI-S group and the SCI-M group was identified $(\mathrm{P}<0.01$; Figs. 2 and 3). The BBB score improved gradually with time and reached the peak at 28 days after injury with a significant difference between the SCI-S group and SCI-M group $(\mathrm{P}<0.01$; Fig. 1). Therefore, a correlation analysis was performed between $A \beta$ levels in serum or CSF and recovery hind limb function (BBB score). The serum and CSF A $\beta$ levels at 3 days after injury were plotted against the BBB score at 28 days after injury for each sample respectively (for the SCI-S, SCI-Mo and SCI-M groups). A significant negative correlation was identified between the two parameters in the $A \beta$ levels in serum $(\mathrm{P}<0.01 ;$ Fig. 6A) and CSF $(\mathrm{P}<0.01$; Fig. 6B).

\section{Discussion}

The present study determined that there was a significant negative correlation between $\mathrm{A} \beta$ protein levels in the CSF and 


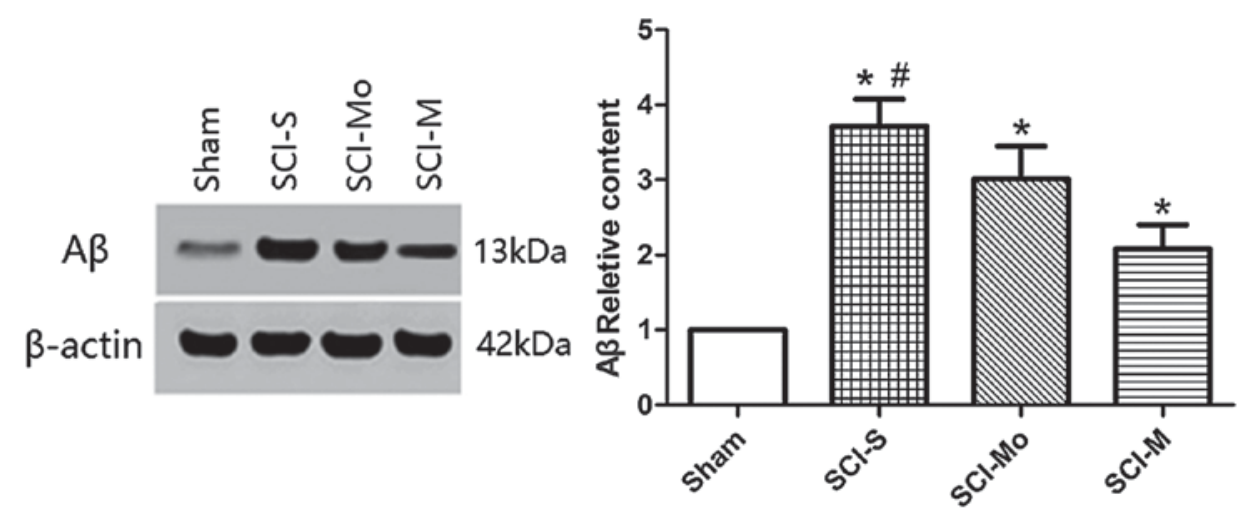

Figure 5. A $\beta$ protein levels in injured spinal cord tissue at 3 days after injury $(\mathrm{n}=4)$. ${ }^{*} \mathrm{P}<0.05$ vs. sham group. ${ }^{*} \mathrm{P}<0.05$ vs. SCI-M group. A $\beta$, amyloid- $\beta$; SCI, spinal cord injury; SCI-M, SCI-mild group; SCI-Mo, SCI-moderate group; SCI-S, SCI-severe group.
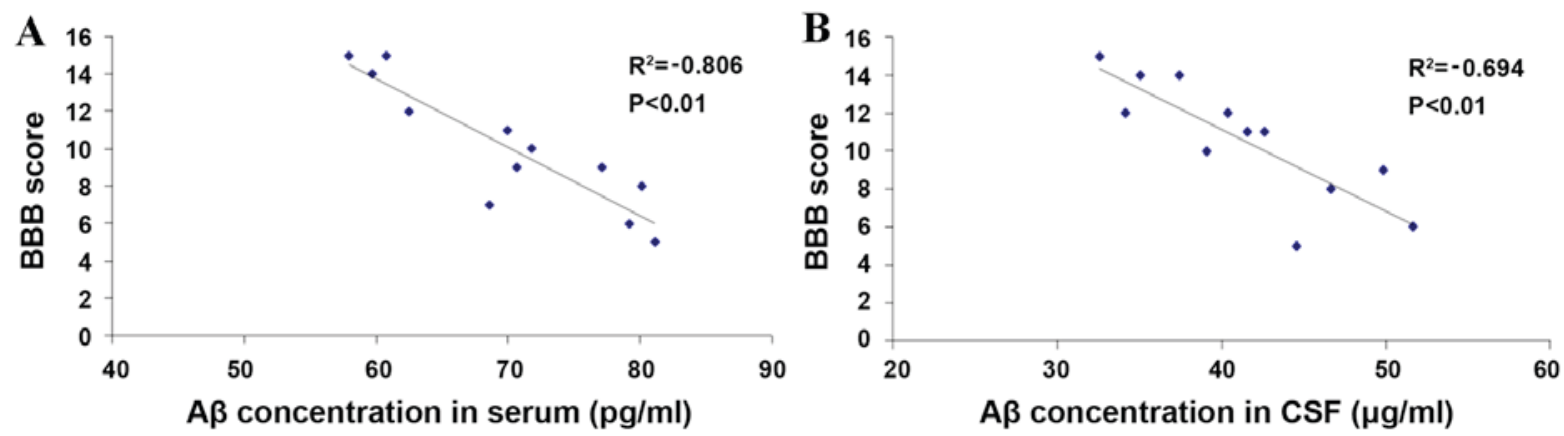

Figure 6. Correlation analysis of serum and CSF A $\beta$ protein levels with BBB score. Rats from all SCI groups from the BBB measurements at 28 days after injury, were used for the correlation. (A) Correlation of serum $A \beta$ levels at 3 days after injury with $B B B$ score at 28 days after injury $(n=12)$. Pearson $R^{2}=-0.806$; $\mathrm{P}<0.01$. (B) Correlation of CSF $A \beta$ levels at 3 days after injury with $B B B$ score at 28 days after injury $(n=12)$. Pearson $\mathrm{R}^{2}=-0.694 ; \mathrm{P}<0.01$. $\mathrm{BBB}$ score, Basso, Beattie and Bresnahan score; A $\beta$, amyloid- $\beta$; CSF, cerebrospinal fluid; SCI, spinal cord injury; SCI-M, SCI-mild group; SCI-Mo, SCI-moderate group; SCI-S, SCI-severe group.

serum and the BBB score of rats with traumatic spinal cord injury.

Spinal cord injury results in mortality and morbidity and currently there are a limited number of effective treatments. The association between inflammation and secondary damage led to the use of a high dose of methylprednisolone therapy within $8 \mathrm{~h}$ of injury, and the common surgical procedures made by physicians are stabilization and decompression of spinal cord (2). Successful management of SCI requires an appropriate diagnostic standard following injury, particularly in the first 3 days, which is the acute phase. Neurological examinations provide a general indication of spinal cord neurological function; however, they may be unreliable, particularly during the acute phase following SCI due to spinal shock in patients (2). Neurophysiological examinations, such as determination of somatosensory evoked potentials and motor evoked potentials, are rarely performed in the acute phase due to their low sensitivity at this time (1). MRI has been established as the gold standard for anatomical SCI diagnosis; however, it may not always be able to distinguish neuronal tissue necrosis from apoptosis and edema $(5,6)$.

Serum biomarker examination may provide a quantitative approach for the assessment of real-time tissue injuries and may be useful for making clinical diagnoses. CSF is in direct contact with the CNS and the spinal cord, which may reflect the biochemical state of the central and periphery nervous system under different physiological and pathological conditions (4). Therefore, CSF may be regarded as a potential source for identifying biomarkers for neurological diseases and trauma. A previous study demonstrated that quantifying the blood or CSF level of neuron- or astroglia-specific proteins may be a more sensitive way to assess the severity of traumatic brain injury (TBI) (7). It has been proposed that CSF, which surrounds and protects the brain and spinal cord from traumatic injury, may be a potential target for the diagnosis of a variety of conditions, including TBI and SCI, in addition to Alzheimer's disease, amyotrophic lateral sclerosis (ALS) and multiple sclerosis (MS) (10-12). Due to the complexity of biofluids; however, considerable developments are required in the analytical techniques used in order to achieve comprehensive coverage of the proteins present in CSF samples. An ideal biomarker should be exclusively intracellular and present in high concentrations.

$\mathrm{A} \beta$ has long been used as potentially useful diagnostic biomarker for brain injury. The $\mathrm{A} \beta$ peptide is produced by proteolytic cleavage of amyloid precursor protein (APP) by two different enzymes, $\beta$ - and $\gamma$-secretase $(20,21)$. A $\beta$ is derived from the transmembrane APP by proteolytic processing during normal cell metabolism and secreted into the CSF, so the CSF $A \beta$ can serve as the foundation for an $A \beta$ biomarker. The 42-amino acid form of $\mathrm{A} \beta\left(\mathrm{A} \beta_{1-42}\right)$ is of special interest, 
as it may have the greatest propensity to deposit into insoluble plaques, which is the pathological characteristic of Alzheimer's disease. Additionally, it may also aggregate into oligomeric $\mathrm{A} \beta$ species, reported to be particularly neurotoxic (22-24). Increased level of APP, $\beta$ - and $\gamma$-secretase, and A $\beta$ have been observed with the onset of numerous other neurological disorders, including ALS, MS and microglia activation and associated neuroinflammation $(10,11,25,26)$. When the axon is severely injured, APP and A $\beta$ are released into the extracellular space via the damaged membrane. Brody et al (13) reported an increase of APP and A $\beta$ levels in the CSF and peripheral blood following TBI and the increases were positively associated with the severity of injury; however, they were negatively correlated with the functional outcome (13). The purpose of the current study was to determine whether $A \beta$ protein expression level may be used as a diagnostic marker for SCI in an animal model.

The rat model of SCI in the present study was modified from the methods described by Wrathall et al (27). The severity of SCI was positively associated with the height from which the weight was dropped. The current study did not identify any significant differences between the $A \beta$ protein levels in the sham group and the SCI-M and SCI-Mo groups $12 \mathrm{~h}$ after injury. However, a significant increase in serum and CSF A $\beta$ protein levels was observed in the SCI-S group at $12 \mathrm{~h}$. A $\beta$ protein levels peaked at 3 days after injury in all SCI groups, therefore it may accurately reflect the severity during the acute phase of SCI. A previous study suggested that the accumulation of $\beta$-APP and increase of $A \beta$ peptide in injured spinal cord tissue were accompanied by axonal dysfunction within 1 day of SCI (28), with a peak at 3 days after injury (29), which is similar to the findings of the present study demonstrated by ELISA and western blotting. The serum and CSF $A \beta$ levels changed similarly with the $A \beta$ level in injured spinal cord tissue, which determined that the $\mathrm{A} \beta$ levels in biofluids may predict the alterations that occur in injured tissue. High levels of $A \beta$ in the CSF may reflect the reduced clearance of APP and the increased deposition of $A \beta$ in injured spinal cord tissue. At $12 \mathrm{~h}$ after injury, although $\mathrm{A} \beta$ protein level in the SCI-S group was higher compared with in the sham group, the graded SCI groups did not differ significantly until 1 day after injury. These results are consistent with previous studies on SCI $(15,28,29)$. SCI-S group was significantly different when compared with the SCI-M and SCI-Mo groups at 28 days after injury in the serum and CSF, which may indicate a long-lasting axonal transport destruction and deposition of $\mathrm{A} \beta$ protein as a result of cleavage of APP in the lesion site. By contrast to Pajoohesh-Ganji et al (15) where the $A \beta$ expression in injured spinal cord tissue returned to baseline levels at 7 days after injury, the present study revealed the long-lasting increase of $\mathrm{A} \beta$ levels in serum and CSF in the SCI-S group may be due to severe destruction of spinal cord and blood-brain barrier, whereas A $\beta$ levels in SCI-M and SCI-Mo groups were consistent with the findings of Pajoohesh-Ganji et al (15).

In conclusion, the present study indicated that serum and CSF A $\beta$ protein level alterations are time-dependent. The peak in the concentration of the biomarker may reflect the mechanical disruption of the spinal cord and blood-brain barrier. The concentrations of the biomarker were negatively correlated with the BBB score. The current study suggested that $\mathrm{A} \beta$ protein may be used as a specific biomarker for SCI diagnosis. This biomarker may also be used for screening of degenerative changes following SCI.

\section{Acknowledgements}

The present study was supported by the National Natural Science Foundation of China (grants nos. 81301679 and 81671211).

\section{References}

1. Krishna V, Andrews H, Varma A, Mintzer J, Kindy MS and Guest J: Spinal cord injury: How can we improve the classification and quantification of its severity and prognosis? J Neurotrauma 31: 215-227, 2014.

2. Silva NA, Sousa N, Reis RL and Salgado AJ: From basics to clinical: A comprehensive review on spinal cord injury. Prog Neurobiol 114: 25-57, 2014.

3. Pouw MH, Hosman AJ, van Middendorp JJ, Verbeek MM, Vos PE and van de Meent H: Biomarkers in spinal cord injury. Spinal Cord 47: 519-525, 2009.

4. Pouw MH, Kwon BK, Verbeek MM, Vos PE, van Kampen A, Fisher CG, Street J, Paquette SJ, Dvorak MF, Boyd MC, et al: Structural biomarkers in the cerebrospinal fluid within $24 \mathrm{~h}$ after a traumatic spinal cord injury: A descriptive analysis of 16 subjects. Spinal Cord 52: 428-433, 2014.

5. Cheran S, Shanmuganathan K, Zhuo J, Mirvis SE, Aarabi B, Alexander MT and Gullapalli RP: Correlation of MR diffusion tensor imaging parameters with ASIA motor scores in hemorrhagic and nonhemorrhagic acute spinal cord injury. J Neurotrauma 28: 1881-1892, 2011.

6. Yokobori S, Zhang Z, Moghieb A, Mondello S, Gajavelli S, Dietrich WD, Bramlett H, Hayes RL, Wang M, Wang KK, Bullock MR, et al: Acute diagnostic biomarkers for spinal cord injury: Review of the literature and preliminary research report. World Neurosurg 83: 867-878, 2015.

7. Li K, Nicaise C, Sannie D, Hala TJ, Javed E, Parker JL, Putatunda R, Regan KA, Suain V, Brion JP, et al: Overexpression of the astrocyte glutamate transporter GLT1 exacerbates phrenic motor neuron degeneration, diaphragm compromise and forelimb motor dysfunction following cervical contusion spinal cord injury. J Neurosci 34: 7622-7638, 2014.

8. Chen L, Wang X, Bao J, Geng C, Xia Y and Wang J: Direct comparison of cardiovascular magnetic resonance and single-photon emission computed tomography for detection of coronary artery disease: A meta-analysis. PLoS One 9: e88402, 2014.

9. Hou JM, Yan RB, Xiang ZM, Zhang H, Liu J, Wu YT, Zhao M, Pan QY, Song LH, Zhang W, et al: Brain sensorimotor system atrophy during the early stage of spinal cord injury in humans. Neuroscience 266: 208-215, 2014.

10. Ikonomovic MD, Uryu K, Abrahamson EE, Ciallella JR, Trojanowski JQ, Lee VM, Clark RS, Marion DW, Wisniewski SR and DeKosky ST: Alzheimer's pathology in human temporal cortex surgically excised after severe brain injury. Exp Neurol 190: 192-203, 2004.

11. Bryson JB, Hobbs C, Parsons MJ, Bosch KD, Pandraud A, Walsh FS, Doherty P and Greensmith L: Amyloid precursor protein (APP) contributes to pathology in the SOD1 (G93A) mouse model of amyotrophic lateral sclerosis. Hum Mol Genet 21: 3871-3882, 2012.

12. Uryu K, Laurer H, McIntosh T, Praticò D, Martinez D, Leight S, Lee VM and Trojanowski JQ: Repetitive mild brain trauma accelerates Abeta deposition, lipid peroxidation, and cognitive impairment in a transgenic mouse model of Alzheimer amyloidosis. J Neurosci 22: 446-454, 2002.

13. Brody DL, Magnoni S, Schwetye KE, Spinner ML, Esparza TJ, Stocchetti N, Zipfel GJ and Holtzman DM: Amyloid-beta dynamics correlate with neurological status in the injured human brain. Science 321: 1221-1224, 2008.

14. Mondello S, Buki A, Barzo P, Randall J, Provuncher G, Hanlon D, Wilson D, Kobeissy F and Jeromin A: CSF and plasma amyloid- $\beta$ temporal profiles and relationships with neurological status and mortality after severe traumatic brain injury. Sci Rep 4: 6446, 2014. 
15. Pajoohesh-Ganji A, Burns MP, Pal-Ghosh S, Tadvalkar G, Hokenbury NG, Stepp MA and Faden AI: Inhibition of amyloid precursor protein secretases reduces recovery after spinal cord injury. Brain Res 1560: 73-82, 2014.

16. Agrawal G, Kerr C, Thakor NV and All AH: Characterization of graded multicenter animal spinal cord injury study contusion spinal cord injury using somatosensory-evoked potentials. Spine (Phila Pa 1976) 35: 1122-1127, 2010.

17. Basso DM, Beattie MS and Bresnahan JC: A sensitive and reliable locomotor rating scale for open field testing in rats J Neurotrauma 12: 1-21, 1995.

18. Loane DJ, Pocivavsek A, Moussa CE, Thompson R, Matsuoka Y, Faden AI, Rebeck GW and Burns MP: Amyloid precursor protein secretases as therapeutic targets for traumatic brain injury. Nat Med 15: 377-379, 2009.

19. Byrnes KR, Stoica BA, Fricke S, Di Giovanni S and Faden AI Cell cycle activation contributes to post-mitotic cell death and secondary damage after spinal cord injury. Brain 130: 2977-2992, 2007.

20. Hu X, Hicks CW, He W, Wong P, Macklin WB, Trapp BD and Yan R: Bacel modulates myelination in the central and peripheral nervous system. Nat Neurosci 9: 1520-1525, 2006.

21. Selkoe DJ; American College of Physicians; American Physiological Society: Alzheimer disease: Mechanistic understanding predicts novel therapies. Ann Intern Med 140: 627-638, 2004.

22. Walsh DM, Klyubin I, Fadeeva JV, Cullen WK, Anwyl R, Wolfe MS, Rowan MJ and Selkoe DJ: Naturally secreted oligomers of amyloid beta protein potently inhibit hippocampal long-term potentiation in vivo. Nature 416: 535-539, 2002.
23. Lesné S, Koh MT, Kotilinek L, Kayed R, Glabe CG, Yang A, Gallagher $\mathrm{M}$ and Ashe KH: A specific amyloid-beta protein assembly in the brain impairs memory. Nature 440: 352-357, 2006.

24. Shankar GM, Li S, Mehta TH, Garcia-Munoz A, Shepardson NE, Smith I, Brett FM, Farrell MA, Rowan MJ and Lemere CA: Amyloid-beta protein dimers isolated directly from Alzheimer's brains impair synaptic plasticity and memory. Nat Med 14: 837-842, 2008.

25. Matsuoka Y, Picciano M, Malester B, LaFrancois J, Zehr C, Daeschner JM, Olschowka JA, Fonseca MI, O'Banion MK, Tenner AJ, et al: Inflammatory responses to amyloidosis in a transgenic mouse model of Alzheimer's disease. Am J Pathol 158: 1345-1354, 2001.

26. Wyss-Coray T and Mucke L: Inflammation in neurodegenerative disease-a double-edged sword. Neuron 35: 419-432, 2002.

27. Wrathall JR, Pettegrew RK and Harvey F: Spinal cord contusion in the rat: Production of graded, reproducible, injury groups. Exp Neurol 88: 108-115, 1985.

28. Kobayashi S, Sasaki T, Katayama T, Hasegawa T, Nagano A and Sato K: Temporal-spatial expression of presenilin 1 and the production of amyloid-beta after acute spinal cord injury in adult rat. Neurochem Int 56: 387-393, 2010.

29. Ward RE, Huang W, Kostusiak M, Pallier PN, Michael-Titus AT and Priestley JV: A characterization of white matter pathology following spinal cord compression injury in the rat. Neuroscience 260: 227-239, 2014. 